\title{
Irrigation and Crop Load Influence Fruit Size and Water Relations in Field-grown 'Spadona' Pear
}

\author{
Amos Naor \\ The Golan Research Institute, P. O. Box 97, Kazrin 12900, Israel
}

\begin{abstract}
AdDitional INDEX WORDS: water potential, stomatal conductance
Abstract. Interrelations between water potential and fruit size, crop load, and stomatal conductance were studied in dripirrigated 'Spadona' pear (Pyrus communis $\mathrm{L}$ ) grafted on quince C (Cydonia oblonga $\mathrm{L}$.) rootstock and growing in a semi-arid zone. Five irrigation rates were applied in the main fruit growth phase: rates of $0.25,0.40,0.60,0.80$, and 1.00 of "Class $A$ " pan evaporation rate. The crop in each irrigation treatment was adjusted to four levels ( 200 to 1200 fruit per tree) by hand thinning at the beginning of June 1999. The crop was harvested on 1 Aug. 1999, and fruit size was determined by means of a commercial sorting machine. Soil, stem, and leaf water potentials and stomatal conductance were measured during the season. Crop yield was highly correlated with stem and soil water potentials. The highest midday stem water potential was lower than values commonly reported for nonstressed trees, and was accompanied by high soil water potential, indicating that the maximal water absorption rate of the root system under those particular soil conditions was limited. Stomatal conductance was highly correlated with leaf water potential $\left(r^{2}=0.54\right)$, but a much better correlation was found with stem water potential $\left(r^{2}=0.80\right)$. Stomatal conductance decreased at stem water potentials less than -2.1 MPa. Both stem water potential and stomatal conductance were unaffected by crop load under a wide range of irrigation rates.
\end{abstract}

Interactions between irrigation and crop load, and their effects on yield, fruit size, and tree-water relations have been studied in many fruit trees. Numerous studies have reported positive effects of fruit on assimilation rate, stomatal and mesophyll conductance, transpiration, and biomass production (Flore and Lakso, 1989). Fruit-bearing trees have higher stomatal conductance than defruited trees (Downton et al., 1987; Hansen, 1971; Lenz, 1986; Loveys and Kriedemann, 1974). Stem water potentials of stressed apple [Malus sylvestris (L.) Mill. var. domestica (Borkh.) Mansf.] (Naor et al., 1997c) and nectarine [Prunus persica (L.) Batsch var. (Nectarine Group)] (Berman and DeJong, 1996; Naor et al., 2001) have been reported to decrease with increasing crop load, but other studies have found that crop load did not affect leaf water potential in apple (Erf and Proctor, 1987). Crop load did not affect stem water potential in nectarine up to 1000 fruit per tree (Naor et al., 1999), but Naor et al. (2001) found a clear decrease in stem water potential as crop load increased above 1000 fruit per tree in both stressed and nonstressed nectarines. Midday stem water potential in nectarine decreased (Berman and DeJong, 1996; Naor et al., 2001) when a source limitation (DeJong and Grossman, 1995) was apparent.

Midday stem water potential was proposed as a plant water stress indicator (Garnier and Berger, 1985; McCutchan and Shackel, 1992; Naor et al., 1995, 1997c, 1999; Shackel et al., 1997; Stern et al., 1998). It has been found to be more sensitive to irrigation regime than midday leaf water potential (Garnier and Berger, 1985; McCutchan and Shackel, 1992; Naor et al., 1995; Stern et al., 1998) or soil water potential (Naor et al., 1995, 1997c, 1999). Stomatal conductance was better correlated with stem water potential than with leaf water potential in apple, grape (Vitis vinifera, L.) and nectarine (Naor, 1998). Fruit weight decreased with decreasing midday stem water potential in apple (Naor et al., 1997c), nectarine (Berman and DeJong, 1996; Naor et al., 1999) and pear (Pyrus communis L.) (Ramos et al., 1994; Shackel et al., 1997). Fruit weight also decreased with increasing crop load in apple (Naor et al., 1997b), nectarine (Berman and Dejong, 1996;

Received for publication 2 Feb. 2000. Accepted for publication 10 Nov. 2000. The cost of publishing this paper was defrayed in part by the payment of page charges. Under postal regulations, this paper therefore must be hereby marked advertisement solely to indicate this fact.
Naor et al., 1999), and Asian pear (Pyrus serotina Rehd.)(Buwalda et al., 1989).

The relevancy and applicability of midday stem water potential for irrigation scheduling of pear was not tested in the past except for the high correlation between midday stem water potential and average fruit size (Ramos et al., 1994). Therefore, the objectives of this investigation were to 1) study the combined effects of irrigation and crop load on the relations between pear fruit size and water potential, and 2) study the relationships among stomatal conductance, soil water potential, leaf water potential and stem water potential in order to find physiological meanings to the thresholds for irrigation scheduling.

\section{Materials and Methods}

Climatic conditions. The experimental site was located in Upper Galilee, Israel (lat. $33^{\circ} \mathrm{N}$, long. $36^{\circ} \mathrm{E}$ ), $310 \mathrm{~m}$ above mean sea level, which is a semi-arid zone with no summer rain. Average annual precipitation (October-April) in this region is $\approx 550 \mathrm{~mm}$.

EXPERIMENTAL PLOT. The experimental plot consisted of a 15year-old drip-irrigated commercial orchard of 'Spadona' pear grafted on quince C (Cydonia oblonga Mill) rootstock spaced $2.25 \times 4.5 \mathrm{~m}$ apart. Soil type was a brown-alluvial gromosol with the soil profile deeper than $1 \mathrm{~m}$. The irrigation system consisted of two lateral lines per row spaced $1.0 \mathrm{~m}$ apart, with $2.3-\mathrm{L} \cdot \mathrm{h}^{-1}$ pressure-compensated, in-line drippers (Netafim, Iftach, Israel), spaced $0.75 \mathrm{~m}$ apart.

IRRIGATION TREATMENTS. Irrigation at the beginning of the season was started once the soil water potential at $60-\mathrm{cm}$ depth reached $-40 \mathrm{kPa}$, as measured by tensiometers (see below). Thereafter, the soil water potential at a $60-\mathrm{cm}$ depth was maintained near $-15 \mathrm{kPa}$ until 1 June. Five irrigation rates (fractions of Class A pan evaporation rate, $0.25,0.40,0.60,0.80$, or 1.00 ) were applied from 1 June until 1 Aug. (harvest), which is the main fruit growth phase. Pan evaporation was measured at a distance of 150 $\mathrm{m}$ from the experimental plot. The treatments are designated below as $0.25-\mathrm{K}_{\mathrm{C}}, 0.40-\mathrm{K}_{\mathrm{C}}, 0.60-\mathrm{K}_{\mathrm{C}}, 0.80-\mathrm{K}_{\mathrm{C}}$, and $1.00-\mathrm{K}_{\mathrm{C}}$.

Crop LOAd TREaTMEnTs. Fruit on each tree were counted at the beginning of June and thinned to four approximate yield targets: 10, 20, 30, and $45 \mathrm{t} \cdot \mathrm{ha}^{-1}$. However, the actual fruit levels (200 to 
1200 fruit/tree) measured at harvest were used for data analysis.

YIELD AND FRUIT SIZE MEASUREMENTS. Fruit from each tree was harvested and weighed on 1 Aug. 1999, and the fruit-size distribution was determined by means of a commercial sorting machine (Pennwalt, Decco-Rodda, Bertinora, Italy) separating from 40 to $65 \mathrm{~mm}$ at $5 \mathrm{~mm}$ increments.

SoIL WATER POTENTIAL MEASUREMENTS. Three tensiometers (Irrometer, Riverside, Calif.) were installed at 30, 60, and 90-cm depths in each irrigation plot of the $0.25-\mathrm{K}_{\mathrm{C}}, 0.40-\mathrm{K}_{\mathrm{C}}, 0.60-\mathrm{K}_{\mathrm{C}}$, and $0.80-\mathrm{K}_{\mathrm{C}}$ treatments, in mid-May; they were installed at the $90-\mathrm{cm}$ depth in the $1.00-\mathrm{K}_{\mathrm{C}}$ treatment in mid-July. The tensiometers were located $20 \mathrm{~cm}$ from an emitter and close to the trunk of trees with medium crop loads. Tensiometer readings (five per treatment) were taken in the morning, before irrigation had started. In the first 3 weeks after installation, tensiometers with irregular readings were reinstalled to improve uniformity.

STEM AND LEAF WATER POTENTIAL, AND STOMATAL CONDUCTANCE MEASUREMENTS. Leaf water potential was measured on two sun-exposed leaves per tree, by means of a pressure chamber (Ari-Mad, Kfar Charuv, Israel) (Scholander et al., 1965). Stem

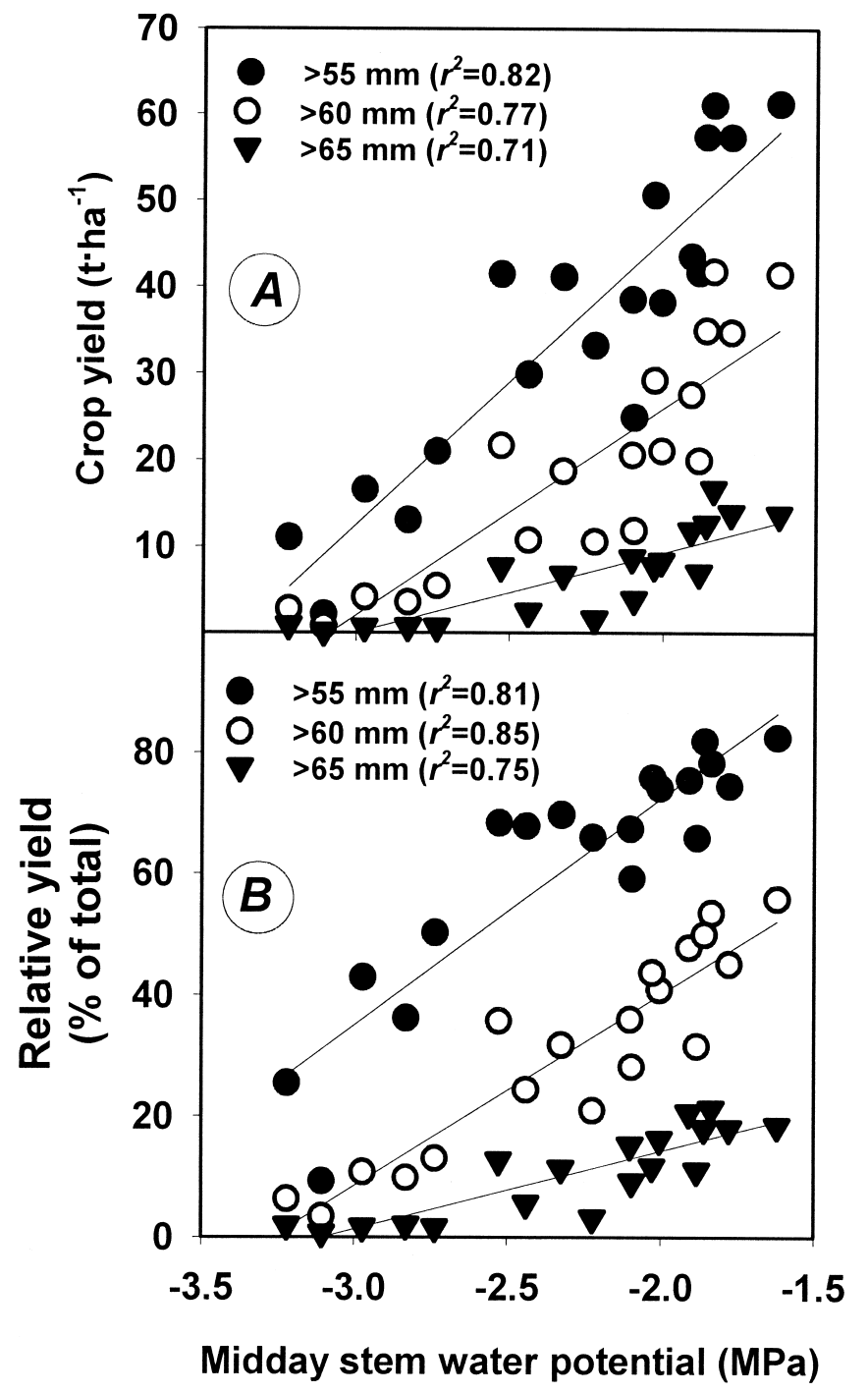

Fig. 1. (A) Crop yield (t.ha ${ }^{-1}$ ) and (B) relative yield (\% of total) as functions of average midday stem water potential in July 1999. Trees of medium crop load (400 to 600 fruit per tree) were included. water potential was measured as follows. Two leaves per tree were sampled from the inner part of the canopy; they were enclosed, while still attached, in plastic bags covered with aluminum foil. After an equilibrating period of $90 \mathrm{~min}$, the leaves were detached from the shoot, and stem water potential was determined immediately with a pressure chamber. Stomatal conductance was measured with a porometer (LI-1600, LI-COR, Lincoln, Nebr.); two sun-exposed leaves per tree were measured. Midday stem water potential was measured once a week starting at 1 PM (daylight saving time). Simultaneous measurements of midday stem water potential and stomatal conductance were performed on 14 July in the $0.25-\mathrm{K}_{\mathrm{C}}, 0.60-\mathrm{K}_{\mathrm{C}}$, and $1.00-\mathrm{K}_{\mathrm{C}}$ treatments. Diurnal measurements of stem and leaf water potential as well as stomatal conductance were conducted on 7 July at $9 \mathrm{AM}, 11 \mathrm{AM}$, and $1 \mathrm{PM}$. Positions of leaf and stem water potential measurements were $\approx 1.5 \mathrm{~m}$ apart. Stem and leaf water potential and stomatal conductance measurements were taken on those trees nearest tensiometers except for $14 \mathrm{July}$, when measurements were taken on trees of all crop loads in the $0.25-\mathrm{K}_{\mathrm{C}}, 0.60-\mathrm{K}_{\mathrm{C}}$, and $1.0-\mathrm{K}_{\mathrm{C}}$ treatments.

EXPERIMENTAL DESIGN AND STATISTICAL ANALYSIS. The experimental design was a split plot with a factorial arrangement of treatments, with five irrigation levels as main plots and crop load as subplots. Treatments were replicated five times in a completely randomized block design. Each main plot (irrigation treatment) consisted of four trees surrounded by border trees.

Relationships between yield, and soil and stem water potentials were studied in trees having medium crop loads only (400 to 600 fruit/tree). Average soil water potential $(0-90 \mathrm{~cm})$ and average midday stem water potential in July were calculated for each tree, and a linear regression was developed. A sigmoid $[\mathrm{y}=$ $\mathrm{a} /\left(1+\exp \left(-\left(\mathrm{x}-\mathrm{x}_{0}\right) / \mathrm{b}\right)\right]$ regression was developed to the relationships between stomatal conductance and leaf and stem water potential and to the relationships between yield of fruit $>55 \mathrm{~mm}$ in diameter and soil water potential. The lower and upper values at which the sigmoid curve starts to level off where estimated graphically using the second derivative with respect to water potential (McMeekin et al., 1993).

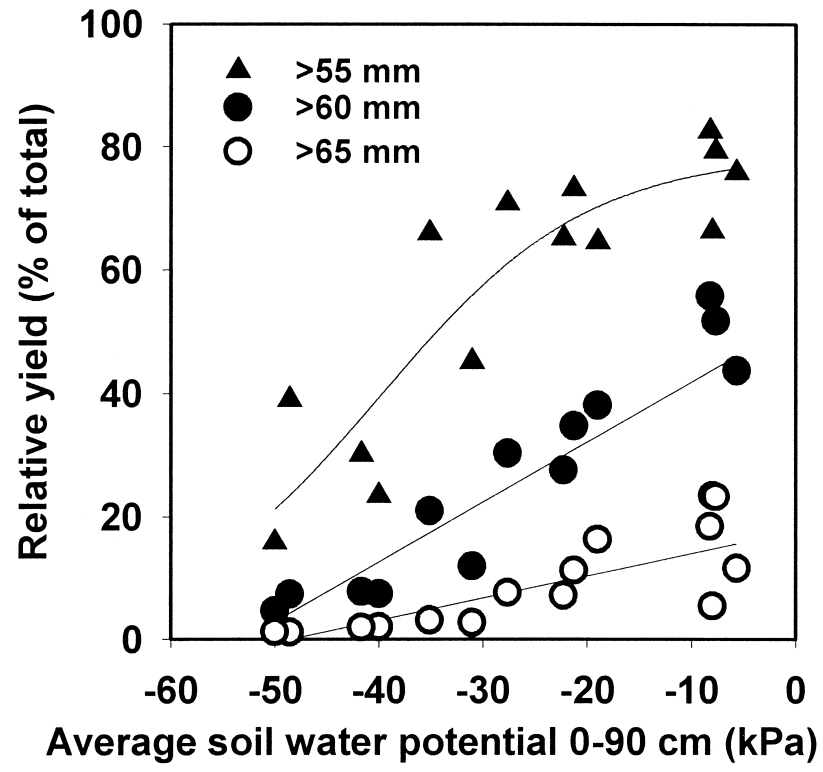

Fig. 2. Relative yield ( $\%$ of total) as a function of average soil water potential in July 1999. Trees of medium crop load (400 to 600 fruit/tree) were included. 


\section{Results}

IRRIGATION. Cumulative irrigation levels from the beginning of the season until harvest were $271,351,465,572$, and $688 \mathrm{~mm}$ in the $0.25-\mathrm{K}_{\mathrm{C}}, 0.40-\mathrm{K}_{\mathrm{C}}, 0.60-\mathrm{K}_{\mathrm{C}}, 0.80-\mathrm{K}_{\mathrm{C}}$, and $1.00-\mathrm{K}_{\mathrm{C}}$ treatments, respectively. The crop coefficients [applied irrigation in millimeter/Class A pan evaporation rate in millimeter] during the main fruit expansion phase were close to the planned values.

Yield AND WATER POTENTIAL. Yields of fruit exceeding 55, 60, and $65 \mathrm{~mm}$ in diameter were highly correlated with the midday stem water potential (Fig. 1A). The relative yields of fruit exceeding 55, 60, and $65 \mathrm{~mm}$ in diameter were highly correlated with the midday stem water potential (Fig. 1B).

Relative yields of fruits exceeding 55, 60, and $65 \mathrm{~mm}$ in diameter decreased with decreasing soil water potential (Fig. 2). No fruit exceeding 60 and $65 \mathrm{~mm}$ in diameter would be expected at soil water potentials less than -52 and $-49 \mathrm{kPa}$, respectively.

Water potential and stomatal conductance. Stomatal conductance was correlated with stem water potential (Fig. 3A) and leaf water potential (Fig. 3B). Stem water potential was better correlated with stomatal conductance than leaf water potential. Stomatal conductance was $\approx 15 \%$ of the maximum at stem water potentials less than -2.8 MPa (Fig. 3A); it increased with increasing stem water potential above $-2.8 \mathrm{MPa}$ and started to level off above-2.1 MPa. Stomatal conductance started to decrease at leaf water potentials less than $-2.6 \mathrm{MPa}$.

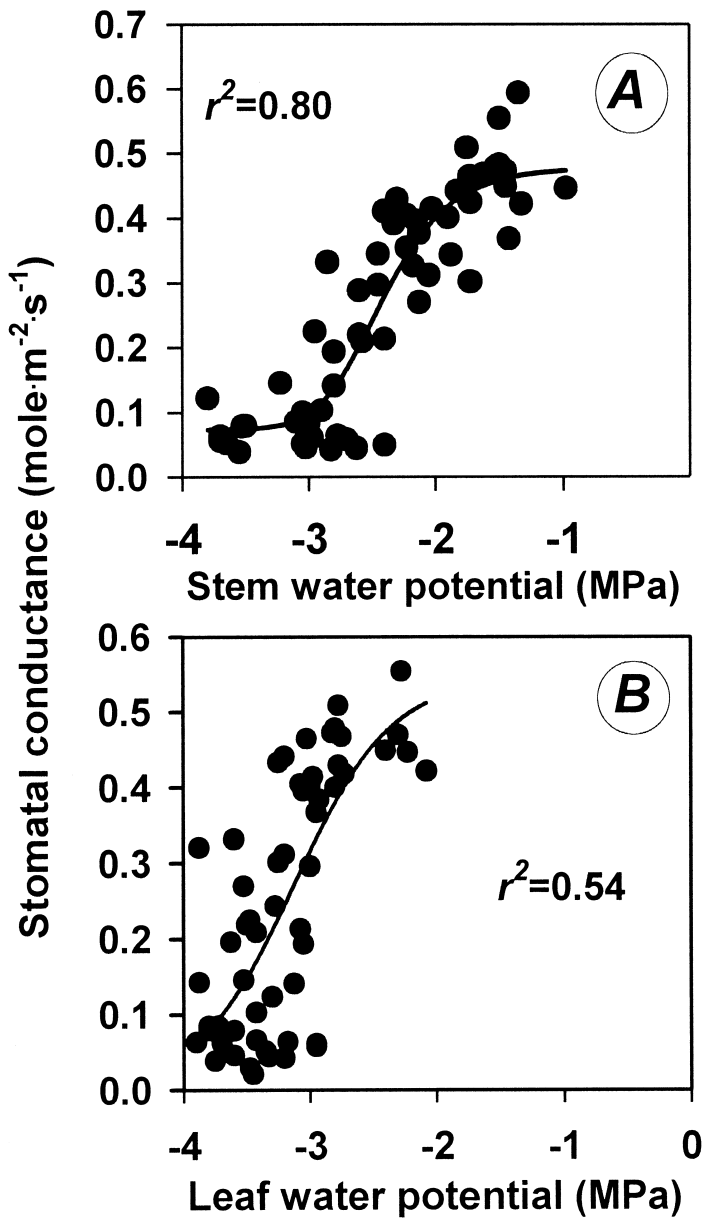

Fig. 3. Relationships between stomatal conductance and (A) stem water potential and (B) leaf water potential derived from diurnal measurements that were taken on 7 July 1999 (9 AM, 11 AM, AND 1 PM). Trees receiving $0.25,0.60$, or 1.00 of Class A pan were used for these measurements.
STEM WATER POTENTIAL, STOMATAL CONDUCTANCE, AND CROP LOAD INTERACTIONS. Midday stem water potential was unaffected by crop load (Fig. 4A). Midday stomatal conductance of the 0.60$\mathrm{K}_{\mathrm{C}}$ and the $1.0-\mathrm{K}_{\mathrm{C}}$ treatments was unaffected by crop load (Fig. $4 \mathrm{~B})$, whereas that of the $0.25-\mathrm{K}_{\mathrm{C}}$ treatment increased slightly with crop load $\left(0.06 \mathrm{~mol} \cdot \mathrm{m}^{-2} \cdot \mathrm{s}^{-1}\right.$ per 1000 fruit $)$. Both midday stem water potential and midday stomatal conductance decreased with decreasing irrigation level (Fig. 4).

\section{Discussion}

Maximum midday stem water potential in this study $(-1.8$ MPa, Fig. 4) was lower than that reported for nonstressed deciduous trees ( -0.5 to $-1.0 \mathrm{MPa}$, Shackel et al., 1997). These low stem water potentials, which prevail in Israel at high soil water potentials (Fig. 2), may indicate that the maximal water absorption rate of the root system is limited. A low midday stem water potential $(-1.3 \mathrm{MPa})$ for well irrigated trees, associated with a similar soil clay content, was reported for nectarine (Naor et al., 1999), which suggests that reduced water absorption rate may be related in part to soil type. It could be attributed to a decrease in soil hydraulic conductivity due to local decrease in soil moisture content in the vicinity of the roots, and also to a low oxygen concentration and high mechanical resistance to root growth.

STEM WATER POTENTIAL, STOMATAL CONDUCTANCE AND CROP LOAD INTERACTIONS. Our data show no effect of crop load on stomatal conductance and midday stem water potential (Fig. 4) except for the $0.25-\mathrm{K}_{\mathrm{C}}$ treatment which showed a slight increase

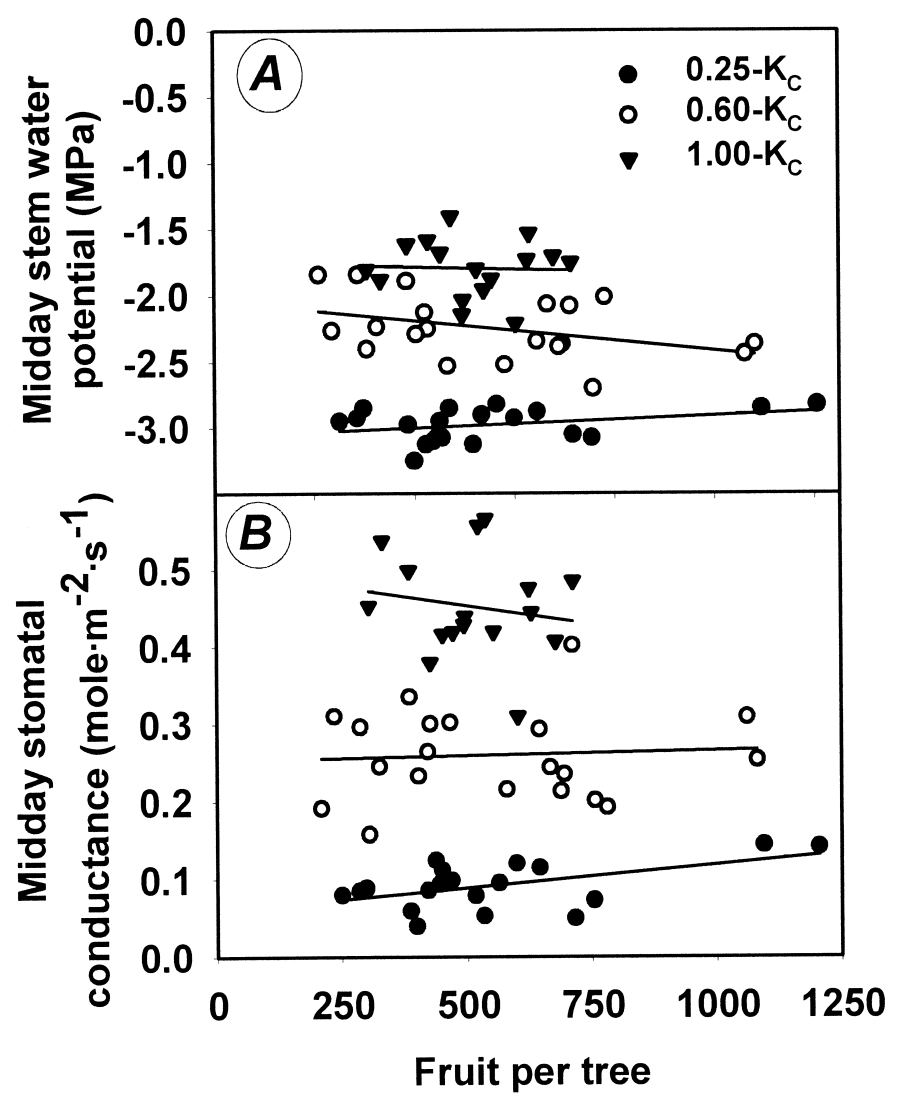

Fig. 4. (A) Midday stem water potential and (B) stomatal conductance as functions of crop load as measured on 14 July 1999 . Trees receiving $0.25,0.60$, or 1.00 of Class A pan were used for these measurements. The slopes of all the lines were not significant at $P=0.05$ except for that which relates the stomatal conductance of the lower irrigation rate to crop load (slope $=0.000006, P=0.02$ ). 
$\left(0.06 \mathrm{~mol} \cdot \mathrm{m}^{-2} \cdot \mathrm{s}^{-1}\right.$ per 1000 fruit $)$ in stomatal conductance with increasing crop load. This agrees with Erf and Proctor (1987), and Naor et al. (1999) and disagrees with Naor et al. (1997a, 1997b), and Berman and DeJong (1996). Naor (1999) reported that the decrease in stem water potential with increasing nectarine crop load was associated with conditions of source limitation (DeJong and Grossman, 1995).

STEM AND LEAF WATER POTENTIALS INTERACTION WITH STOMATAL CONDUCTANCE. The better correlation of stomatal conductance with stem than with leaf water potential is consistent with previous data on apple, nectarine, and grape (Naor, 1998), and this may be related to the fact that stomatal conductance is partially controlled by root signals (Whitehead, 1998). Under such conditions, perturbations in leaf water potential caused by temporal variations in evaporative demand may partially account for the lower correlation of stomatal conductance with leaf water potential. In the present study, stomatal conductance had a sigmoidal relationships with leaf and stem water potentials unlike the linear relationships reported previously for apple, nectarine, and grapevine (Naor, 1998). This seems to be related to the wider range of water potentials in the present study $(2.0$ and $2.8 \mathrm{MPa})$.

A reduction in stomatal conductance occurred only at stem water potentials less than $-2.1 \mathrm{MPa}$, which is a relatively low threshold for stomatal conductance closure. This was accompanied by high values of soil water potential (data not presented) which may suggest that the roots might not have been sufficiently stressed to produce abscisic acid or other root signals, including nonchemical signals that negatively affect conductance (Davies and Zhang, 1991; Whitehead, 1998).

WATER POTENTIAL FOR IRRIGATION SCHEDULING. The correlation between yield and soil water potential was higher than that reported for apple (Naor et al., 1995) and nectarine (Naor et al, 1999). However, the threshold for irrigation scheduling might change with site and year (Naor, unpublished), and it may limit the practical use of soil water potential thresholds. Monitoring trends of soil water potentials rather then the absolute values might be more useful for irrigation scheduling. The high correlation between yield and midday stem water potential (Fig. 1) is in agreement with other findings for pear (Ramos et al., 1994; Shackel et al., 1997), apple (Naor et al., 1997c), and nectarine (Naor et al., 1999). Also, the high correlation of stem water potential with stomatal conductance which was better than that of leaf water potential with stomatal conductance is in agreement with reports on other fruit trees (Naor et al., 1995; Naor, 1998; Stern et al, 1998). Our findings and those of others (Ramos et al., 1994) suggest that midday stem water potential may serve as a plant water status indicator for irrigation scheduling in pear. It may also indicate that tree water requirement does not change considerably with crop load (Fig. 4) in the range that has been reported herein.

\section{Literature Cited}

Berman, M.E. and T.M. DeJong. 1996. Water stress and crop load effects on fruit fresh and dry weights in peach (Prunus persica). Tree Physiol. 16:859-864.

Buwalda, J.G., D.J. Klinac, and J.S. Meekings. 1989. Effects of time and degree of fruit thinning on fruit size and crop yield at harvest for four Nashi (Pyrus seronita Rehd.) cultivars. Scientia Hort. 39:131-141.

Davies, W.J. and J. Zhang. 1991. Root signals and the regulation of growth and development of plants in drying soil. Annu. Rev. Plant Physiol. Plant Mol. Biol. 42:55-76.
DeJong, T.M. and Y.L. Grossman. 1995. Quantifying sink and source limitations on dry matter partitioning of fruit growth in peach trees. Physiol. Plant. 95:437443.

Downton W.J.S., W.J.G. Grant, and B.R. Loveys. 1987. Diurnal changes in the photosynthesis of field-grown grape vines. New Phytol. 105:71-80.

Erf, J.A. and J.T.A. Proctor. 1987. Changes in apple leaf water status and vegetative growth as influenced by crop load. J. Amer. Soc. Hort. Sci. 112:617620.

Flore, J.A. and A.N. Lakso. 1989. Environmental and physiological regulation of photosynthesis in fruit crops. Hort. Rev. 11:111-157.

Garnier, E. and A. Berger. 1985. Testing water potential in peach trees as an indicator of water stress. J. Hort. Sci. 60:47-56.

Hansen, P. 1971. The effect of fruiting upon transpiration rate and stomatal opening in apple leaves. Physiol. Plant. 25:181-183.

Lenz, F. 1986. Fruit effects on transpiration and dry matter production in apples, p. 101-104. In: A.N. Lakso and F. Lenz (eds.). Regulation of photosynthesis in fruit trees. N.Y. State Agr. Expt. Sta., Geneva, Symp. Proc. Publ.

Loveys B.R. and P.E. Kriedemann. 1974. Internal control of stomatal physiology and photosynthesis. I. Stomatal regulation and associated changes in endogenous levels of abscisic and phaseic acids. Austral. J. Plant Physiol. 1:407-415.

McCutchan, H. and K.A. Shackel. 1992. Stem-water potential as a sensitive indicator of water stress in prune trees (Prunus domestica L. cv. French). J. Amer. Soc. Hort. Sci. 117:607-611.

McMeekin, T., J.N. Olley, T. Ross, and D.A. Ratkowsky. 1993. Predictive microbiology: Theory and application. Research Studies Press Ltd., Taunton Somerset, United Kingdom.

Naor, A. 1998. Relationships between leaf and stem water potentials and stomatal conductance in three field-grown woody species. J. Hort. Sci. 73:431-436.

Naor, A. 1999. Midday stem water potential as a plant water stress indicator for irrigation scheduling in fruit trees. 3rd Intl. Symp. on Irrigation of Hort. Crops., 28 June-2 July, 1999, Lisboa, Portugal.

Naor, A., Y. Gal, and B. Bravdo. 1997a. Crop load affects assimilation rate, stomatal conductance, stem water potential and water relations of field-grown 'Sauvignon Blanc' grapevines. J. Expt. Bot. 314:1675-1680.

Naor, A., H. Hupert, Y. Greenblat, M. Peres, and A. Kaufman. 2001. Response of nectarine fruit size and midday stem water potential to irrigation level in stage III of fruit growth and crop load. J. Amer. Soc. Hort. Sci. (in press).

Naor, A., I. Klein, and I. Doron. 1995. Stem water potential and apple fruit size. J. Amer. Soc. Hort. Sci. 120:577-582.

Naor, A., I. Klein, I. Doron, Y. Gal, Z. Ben-David, and B. Bravdo. 1997b. Irrigation and crop load interactions in relation to apple yield and fruit size distribution. J. Amer. Soc. Hort. Sci. 122:411-414.

Naor, A., I. Klein, I. Doron, Y. Gal, Z. Ben-David, and B. Bravdo. 1997c. The effect of irrigation and crop load on stem water potential and apple fruit size. J. Hort. Sci. 72:765-771.

Naor, A., I. Klein, H. Hupert, Y. Greenblat, M. Peres, and A. Kaufman, 1999. Water stress and crop load interactions in relation to nectarine yield, fruit size distribution and water potentials. J. Amer. Soc. Hort. Sci. 124:189-193.

Ramos, D.E., S.A. Weinbaum, K.A. Shackel, L.J. Schwankl, E.J. Mitcham, F.G. Mitchell, R.G. Snyder, and G. McGourty. 1994. Influence of tree water status and canopy position on fruit size and quality of 'Bartlett' pears. Acta Hort. 367:192-200.

Scholander, P.F., H.T. Hammel, E.D. Bradstreet, and E.A. Hemmingsen. 1965. Sap pressure in vascular plants. Science 148:339-346.

Shackel, K.A., H. Ahmadi, W. Biasi, R. Buchner, D. Goldhamer, S. Gurusinghe, J. Hasey, D. Kester, B. Krueger, B.B. Lampinen, G. McGourty, W. Micke, E. Mitcham, B. Olsen, K. Pelletrau, H. Philips, D. Ramos, L. Scheankl, S. Sibbert, R. Snyder, S. Southwick, M. Stevenson, M. Thorpe, S. Weinbaum, and J. Yeager. 1997. Plant water status as an index of irrigation need in deciduous fruit trees. HortTechnology 7:23-29.

Stern R., M. Meron, A. Naor, S. Gazit, B. Bravdo, and R. Wallach. 1998. Effect of autumnal irrigation level in 'Mauritius' lychee on soil and plant water status and following year flowering intensity and yield. J. Amer. Soc. Hort. Sci. 123:150-155.

Whitehead, D. 1998. Regulation of stomatal conductance and transpiration in forest canopies. Tree Physiol. 18:633-644. 